\title{
Racionalidade política neoliberal e regime fiscal: o caso dos Residentes Não Habituais
}

Neoliberal Political Rationality and Tax Regime: The Case of Non-Habitual

Residents

Rationalité politique néolibérale et régime fiscale : le cas des résidents non

habituels

\section{Fernando Ampudia de Haro e Sofia Gaspar}

\section{OpenEdition}

\section{Journals}

Edição electrónica

URL: https://journals.openedition.org/rccs/11878

DOI: $10.4000 /$ rccs. 11878

ISSN: 2182-7435

\section{Editora}

Centro de Estudos Sociais da Universidade de Coimbra

Edição impressa

Data de publição: 1 setembro 2021

Paginação: 5-28

ISSN: 0254-1106

\section{Refêrencia eletrónica}

Fernando Ampudia de Haro e Sofia Gaspar, «Racionalidade política neoliberal e regime fiscal: o caso dos Residentes Não Habituais», Revista Crítica de Ciências Sociais [Online], 125 | 2021, publicado a 30 setembro 2021, consultado a 03 outubro 2021. URL: http://journals.openedition.org/rccs/11878 ; DOI: https://doi.org/10.4000/rccs.11878 


\title{
FERNANDO AMPUDIA DE HARO, SOFIA GASPAR
}

\section{Racionalidade política neoliberal e regime fiscal: o caso dos Residentes Não Habituais}

\begin{abstract}
Este artigo analisa o regime fiscal dos Residentes Não Habituais (RNH) sob uma perspetiva sociológica. Esta análise exige uma dupla reflexão: por um lado, explorar as condições sociais existentes para o seu aparecimento; e por outro, estudar a racionalidade política e o tipo de subjetividade individual que o sustenta. Tal reflexão apoia-se, metodologicamente, nos pressupostos dos estudos da governamentalidade foucaultiana. $\mathrm{O}$ artigo estrutura-se segundo três momentos concretos: 1) caracterização e análise da evolução dos beneficiários do regime $\mathrm{RNH} ; 2$ ) análise do surgimento deste regime no âmbito da crise financeira de 2008; e 3) definição da racionalidade política que inspira o regime. Conclui-se que o regime $\mathrm{RNH}$ é um programa concebido segundo padrões de racionalidade política neoliberal, para além de constituir um procedimento de reprodução dessa mesma racionalidade, mediante a promoção de um modelo de "cidadão económico".
\end{abstract}

Palavras-chave: análise socioeconómica; benefícios fiscais; política neoliberal; regime fiscal; Residentes Não Habituais.

\section{Introdução}

Em 2014, a PricewaterhouseCoopers - empresa multinacional de auditoria e consultadoria fiscal - publicava um dossiê sobre Portugal com o título seguinte: "Europe’s Best Kept Secret" (PricewaterhouseCoopers, 2014). O documento apresentava o país como um espaço privilegiado para receber investidores devido ao seu atraente regime dos Residentes Não Habituais (RNH). As duas possibilidades oferecidas por este regime fiscal são uma taxa plana de $20 \%$ para os rendimentos do trabalho e de $10 \%$ para pensionistas, que estiveram isentos de tributação até 2020 . Segundo a empresa, o segredo bem merecia ser divulgado, pelo menos entre os seus clientes.

Este artigo dedica-se à análise do regime RNH sob uma perspetiva sociológica. Até hoje, este regime foi objeto de diferentes análises provenientes da área do direito e da fiscalidade (Mendes, 2011; Mesquita, 2014; Silva, 2015), que procuraram determinar a sua pertinência legal ou propor 
alterações visando a sua melhoria. No entanto, o regime RNH é também objeto de interesse para a sociologia por diferentes motivos. Por um lado, envolve um processo de legitimação política através do qual é justificada a sua existência perante a opinião pública. Ao mesmo tempo, esse processo relaciona-se com noções de bem comum e de cidadania. Por outro lado, este regime poderá estar vinculado a fenómenos de mobilidade geográfica entre grupos da população com características sociodemográficas particulares. E por último, pressupõe a procura de categorias específicas de indivíduos detentores de atributos económicos diferenciadores. $\mathrm{O}$ regime RNH possui, assim, dimensões que o tornam suscetível de indagação sociológica. Como tal, os objetivos deste artigo são, em primeiro lugar, analisar as condições sociais de emergência do regime RNH e, em segundo lugar, explorar a sua natureza conceptual, isto é, o tipo de racionalidade política que o inspira, assim como o arquétipo de subjetividade individual ao qual está associado. Deste modo, assumimos que o regime RNH é mais do que um objeto de caráter legal e fiscal, uma vez que contém uma série de componentes referentes ao governo das populações, da orientação das suas condutas e das suas mentalidades.

Para satisfazer o primeiro objetivo, recorremos à literatura existente no campo da sociologia fiscal para compreender os processos de concorrência tributária e o contexto global em que se desenvolve. Para o segundo objetivo, optámos, no âmbito metodológico, pelo enfoque neofoucaltiano da governamentalidade (governamental studies) (Burchell et al., 1991; Marinis, 1999). Este enfoque remete para os conceitos de governo e governamentalidade propostos por Michel Foucault nos finais da década de 1970 (Foucault, 2010). Estes foram ampliados posteriormente por um conjunto amplo e heterogéneo de estudos centrados na análise de governo enquanto condução de comportamentos e nos dispositivos e nas técnicas aplicadas para tal condução. Como tal, a perspetiva metodológica adotada permitirá determinar a relação entre os princípios implícitos ao regime RNH, e uma noção concreta de indivíduo moldada por este regime e pelo qual este é moldado.

Globalmente, este artigo possui uma natureza essencialmente teórica, embora com referência a elementos empíricos para ilustrar certas relações e dimensões relevantes para o núcleo da argumentação. Dada essa natureza, desenvolvemos uma lógica hipotético-dedutiva assente na exploração de conceitos teóricos e nas suas associações lógicas a partir da literatura existente neste domínio.

$\mathrm{O}$ artigo inicia com a apresentação das características principais e a evolução do número de beneficiários que usufruiu até hoje do regime $\mathrm{RNH}$. 
$\mathrm{Na}$ segunda secção, procuramos reconstruir as condições sociais de emergência do regime $\mathrm{RNH}$, relacionadas com postulados de dinamização da economia, processos de concorrência fiscal mundial e a conjuntura definida pela crise económico-financeira iniciada nos Estados Unidos da América (EUA) em 2008. A terceira secção ocupa-se da racionalidade política que preside o regime RNH. A atenção centra-se na articulação desenvolvida por este regime entre princípios clássicos da cidadania e elementos de natureza mercantil. Esta articulação é possível graças a um Estado que age como dinamizador e propiciador de: a) mecanismos de mercado como solução aos problemas da vida social; e b) subjetividades concretas vinculadas ao regime RNH. A quarta e última secção é dedicada às principais conclusões alcançadas.

\section{Caracterização do regime RNH}

O regime RNH foi aprovado pelo Decreto-Lei n. $249 / 2009$, de 23 de setembro. A sua conceção foi desenvolvida pelo XVII Governo Constitucional, do Partido Socialista (PS). Embora existam objetivos implícitos, tal como veremos na próxima secção, o propósito explícito desta iniciativa era atrair, mediante um regime fiscal favorável, quadros qualificados e profissionais associados a atividades com elevado valor acrescentado, e reformados e pensionistas capazes de dinamizar a economia portuguesa. A Portaria n. ${ }^{\circ} 12 / 2010$, de 7 de janeiro, modificada pela Portaria n. ${ }^{\circ} 230 / 2019$, de 23 de julho, faz um levantamento dessas profissões com alto valor acrescentado, com correspondência direta da Classificação Portuguesa das Profissões, nomeadamente administradores e gestores de empresas, médicos, professores universitários, engenheiros, cientistas, especialistas em tecnologias de informação ou artistas. Em geral, trata-se de profissões que remetem para o conceito de classes criativas (Florida, 2010), com capacidade para gerar ou transformar conhecimento, e torná-lo no principal ativo de crescimento económico da sociedade da informação.

Os requisitos gerais do regime RNH são os seguintes:

a) Podem usufruir dele os indivíduos que tenham a sua residência fiscal em Portugal. Esta residência vem determinada pela permanência, consecutiva ou interpolada, de mais de 183 dias no país;

b) O beneficiário não pode ter sido tributado em sede de IRS em Portugal nos cinco anos anteriores;

c) A duração do regime é de 10 anos consecutivos, podendo ser renovado;

d) Em termos documentais, os candidatos devem apresentar um certificado de residência fiscal assim como provas de liquidação dos 
impostos dos cinco anos anteriores. Desde 2012, basta apresentar uma declaração para atestar o cumprimento dessa liquidação;

e) $\mathrm{O}$ regime estabelece que os rendimentos do trabalho dependente e os rendimentos empresariais e profissionais sejam submetidos a uma taxa de $20 \%$ de retenção na fonte;

f) Entre 2013 e até à Lei de Orçamento do Estado para 2020, o regime permitiu que quem recebesse pensões de fonte estrangeira, e ao abrigo dos acordos para evitar a dupla tributação, estivesse isento de impostos sobre estas pensões em Portugal. Contudo, a partir de 2020, este regime foi alterado, eliminando-se a isenção fiscal para as pensões e introduzindo a sua tributação a uma taxa fixa de $10 \%$. A partir desta caracterização, é possível identificar o atributo mais destacado do regime RNH: uma fiscalidade favorável para um conjunto restrito de pessoas, a par da possibilidade de não tributação para pensionistas (até 2020) ou da sua tributação em valores competitivos (após 2020). Contudo, Portugal não é um caso único e há exemplos de programas concebidos com objetivos similares em vários países da Europa (Áustria, Bélgica, Chipre, Dinamarca, Finlândia, Grécia, Holanda, Itália, Malta, Suécia, entre outros), ${ }^{1}$ bem como no Canadá, nos EUA, na Nova Zelândia, no Panamá ou no Uruguai (Džankíc, 2019).

A Tabela 1 apresenta a evolução dos beneficiários do regime RNH em Portugal entre 2009 e 2019. Até 15 de março de 2019 existiam 29901 cidadãos que beneficiaram do regime RNH. Se no início o número de pedidos de RNH ocorreu de forma mais lenta, a partir de 2014, num cenário de final da crise financeira e quando Portugal intensificou a sua afluência de turistas, o número de indivíduos a solicitar este regime começou a acentuar-se. As nacionalidades mais frequentes dos beneficiários foram a francesa, britânica, italiana, brasileira, sueca, portuguesa, espanhola, alemã, belga e holandesa. Entre estas nacionalidades destacam-se os franceses, cujo número de cidadãos é o dobro daqueles que se posicionam em segundo lugar (britânicos). Como se constata na Tabela 1 , no top 10 das nacionalidades nove pertencem a países da UE - sendo que apenas uma é extracomunitária (o Brasil). A nacionalidade portuguesa surge como a sexta mais representativa e, dado que um dos critérios do programa exige que o beneficiário não tenha vivido em Portugal nos últimos cinco anos, depreende-se que estes cidadãos sejam emigrantes portugueses com objetivos de retorno ao país. Relativamente aos pensionistas destacam-se uma vez mais os franceses como os mais representativos.

\footnotetext{
1 Para uma análise de programas similares dentro do espaço europeu, pode ver-se Mendes (2011), Mesquita (2014), Silva (2015) e Scherrer e Thirion (2018).
} 
TABELA 1 - Regime dos Residentes Não Habituais em Portugal (1 de janeiro de 2009 a 15 de março de 2019)

\begin{tabular}{|c|c|c|}
\hline \multirow{12}{*}{$\begin{array}{l}\text { Evolução dos beneficiários do } \\
\text { regime RNH }\end{array}$} & 2009 & 18 \\
\hline & 2010 & 166 \\
\hline & 2011 & 285 \\
\hline & 2012 & 384 \\
\hline & 2013 & 844 \\
\hline & 2014 & 2034 \\
\hline & 2015 & 3738 \\
\hline & 2016 & 5477 \\
\hline & 2017 & 7437 \\
\hline & 2018 & 7899 \\
\hline & $2019 *$ & 1619 \\
\hline & TOTAL & 29901 \\
\hline \multirow{10}{*}{$\begin{array}{l}\text { Top } 10 \text { - nacionalidades dos } \\
\text { beneficiários do regime RNH }\end{array}$} & França & 6925 \\
\hline & Reino Unido & 3352 \\
\hline & Itália & 3275 \\
\hline & Brasil & 2898 \\
\hline & Suécia & 2415 \\
\hline & Portugal & 2055 \\
\hline & Espanha & 1307 \\
\hline & Alemanha & 896 \\
\hline & Bélgica & 828 \\
\hline & Países Baixos & 680 \\
\hline \multirow{10}{*}{$\begin{array}{l}\text { Top } 10 \text { - nacionalidades dos } \\
\text { pensionistas do regime } \mathrm{RNH}^{* *}\end{array}$} & França & 3105 \\
\hline & Itália & 1373 \\
\hline & Suécia & 1347 \\
\hline & Reino Unido & 933 \\
\hline & Portugal & 550 \\
\hline & Finlândia & 400 \\
\hline & Bélgica & 298 \\
\hline & Brasil & 256 \\
\hline & Suíça & 235 \\
\hline & Países Baixos & 200 \\
\hline
\end{tabular}

•Entre 1 de janeiro de 2019 e 15 de março de 2019.

"Até 31 de dezembro de 2017.

Fonte: Oliveira (2019). 
De facto, e se considerarmos o peso dos pensionistas no total de cada uma das respetivas nacionalidades beneficiárias do regime $\mathrm{RNH}$, constatamos que os suecos $(55,8 \%)$, os franceses $(44,8 \%)$ e os italianos $(41,9 \%)$ são aqueles que registam valores mais elevados. Os restantes pensionistas a beneficiar do regime são belgas (36\%), holandeses (29,4\%), britânicos $(27,8 \%)$, portugueses $(26,7 \%)$ e brasileiros $(8,8 \%){ }^{2}$

\section{As condições sociais de emergência do regime RNH}

O fenómeno da concorrência é central no enquadramento do Decreto-Lei n. ${ }^{\circ} 249 / 2009$, de 23 de setembro, que cria a figura do $\mathrm{RNH}$, onde se refere a necessidade de delinear "uma estratégia fiscal global assente nos atuais paradigmas da competitividade". Ser competitivo significa, entre outras coisas, aplicar "instrumentos de política fiscal internacional" capazes de funcionar como "fator de atração da localização dos fatores de produção, da iniciativa empresarial e da capacidade produtiva no espaço português". O resultado será a dinamização da economia nacional. Já em 2017, o principal promotor deste regime, Carlos Baptista Lobo, secretário de Estado dos Assuntos Fiscais, confirmava a pretensão do programa: "alterar estruturalmente a posição de Portugal em sede de concorrência fiscal internacional, tendo em vista a otimização das nossas condições naturais de atração" (Lobo, 2017).

$\mathrm{O}$ regime RNH remete para um conjunto de questões que vão além da sua consideração como um sistema de tributação favorável ou competitivo. A sua compreensão passa por situá-lo num quadro amplo de transformações estruturais do capitalismo, entre as quais é especialmente relevante o processo de financeirização. Este conceito designa o protagonismo crescente que têm assumido os mercados financeiros na vida social e económica, ou seja, o capital que circula pelos canais financeiros é predominante face ao capital alocado na economia produtiva (Epstein, 2005; Heilbron, 2005). Este paradigma provocou uma mudança de equilíbrio entre os mercados financeiros e as organizações empresariais e industriais em favor dos primeiros, $\mathrm{o}$ que acabou por privilegiar os dividendos face à política industrial e empresarial desenvolvida a longo prazo (Langley, 2007). As finanças penetraram em todas as áreas da vida (Martin, 2002), de tal modo que certos serviços e produtos financeiros estão hoje presentes, por exemplo, na educação (Erturk et al., 2005), na habitação (Santos, 2018), no fornecimento de

\footnotetext{
2 Os dados sobre a evolução e composição dos RNH são de difícil acesso ao público em geral. Por este motivo, não é possível explorarmos aqui algumas questões que poderiam ser importantes clarificar, nomeadamente a caracterização sociodemográfica ou a localização geográfica dos beneficiários. Um outro aspeto essencial passa pela evolução, dentro do próprio regime, entre o número de indivíduos que o solicitam enquanto profissionais qualificados ou enquanto pensionistas.
} 
água ou nas pensões (Rodrigues et al., 2016), nas relações laborais (Alonso e Fernández Rodríguez, 2012) ou na comunicação social (Clark et al., 2004; Harrington, 2008). Assim, as finanças, apoiadas nas tecnologias da informação e na globalização, lideram hoje a economia mundial. Neste contexto, os Estados tentam chamar para si o capital financeiro e a riqueza gerada pela indústria financeira global, com o intuito desse mesmo capital se materializar em investimentos e consumo dentro das suas fronteiras.

Uma das ferramentas usadas na tentativa de atração de capital é a política fiscal, mais concretamente, as condições de tributação, sendo que na União Europeia (UE) não existe qualquer regulação neste domínio. Os Estados-membros subscrevem, genericamente, uma espécie de "acordo de cavalheiros" ao abrigo de um código de conduta não vinculativo. Mediante o "Código de Conduta no domínio da Fiscalidade das Empresas" os países comprometem-se a não manter políticas fiscais e tributárias danosas para os restantes parceiros. Trata-se de uma declaração de intenções num terreno onde o debate se estrutura em torno de dois polos de tensão (Platform for Tax Governance, 2018; Trautvetter e Winkler, 2019). Por um lado, o nível de impostos é visto como um custo que pode favorecer a competitividade da economia nacional sempre e quando tal nível se mantiver suficientemente baixo. Desse modo, os recursos que, teoricamente, teriam de ser dedicados ao pagamento de impostos, poderiam destinar-se a uma redução do preço dos bens e serviços ou a reinvestir para melhorar a capacidade produtiva. Por outro lado, uma menor arrecadação de impostos, isto é, uma redução da receita fiscal, pode comprometer o financiamento do Estado-providência e, em geral, dos serviços públicos básicos, o que acabaria por tornar o país pouco atrativo para o investimento externo. Neste debate, a UE recomenda uma competição justa e um ponto de equilíbrio entre a aposta pela competitividade e o esforço da coesão social.

A questão que se coloca é se esta recomendação é factível ou se a concorrência fiscal acaba por desencadear uma "corrida para o abismo", ou seja, um nivelamento por baixo das condições tributárias, o que se traduz numa degradação do sistema de bem-estar e das infraestruturas, prejudicando a atratividade do país para os investidores. Eloi Laurent (2007) adverte que esse "abismo" é o resultado expectável da dinâmica concorrencial em matéria fiscal, e que será necessário ter em conta fatores como o tamanho do país, o volume da população ou as restrições institucionais internas para saber quão simétrica ou assimétrica se pode tornar a concorrência. Por exemplo, alguns estudos (Genschel e Schwarz, 2011) sugerem que, para uma parte significativa da mobilidade laboral dentro da UE, o fator 
fiscal não é determinante, mas sim a tentativa de melhoria nos rendimentos. No entanto, entre os contingentes de indivíduos com mais qualificações, as vantagens fiscais parecem ser mais determinantes para explicar a sua mobilidade intraeuropeia. A existência destas assimetrias tem motivado reflexões acerca da estrutura institucional e normativa que devia ter o mercado para evitar desequilíbrios (Xu et al., 2015). Além das consequências previstas ou desejadas da concorrência, sabemos que os países constroem a sua própria escala de atratividade face aos seus concorrentes, vigiando reciprocamente as suas políticas. Nesse sentido, agem e reagem de acordo com os sinais e a informação dos mercados relativamente aos investidores e ao capital humano qualificado existentes. Esta vigilância recíproca permite afinar a sua oferta num processo de avaliação comparativa (benchmarking) constante, refletido em rankings e classificações mundiais (Fougner, 2008; Schachar e Hirschl, 2014).

Às condições estruturais definidas pela financeirização e às dinâmicas concorrenciais entre países acrescem as condições conjunturais associadas à emergência do regime RNH em Portugal. Esta conjuntura relaciona-se com a crise financeira iniciada no mercado das hipotecas subprime nos EUA em 2008, e que chega à Europa em 2010 sob a denominação de crise das dívidas soberanas. Nesse ano, num artigo que recolhe os dois primeiros parágrafos do Decreto-Lei n. ${ }^{\circ}$ 249/2009, de 23 de setembro, no qual é criado o regime RNH, Carlos Baptista Lobo insistia na necessidade de reposicionar Portugal numa estratégia fiscal competitiva que, ao mesmo tempo, contribuísse para suavizar o impacto da crise que se avizinhava (Lobo, 2010). Com o agravamento da crise e no marco do Programa de Assistência Económica e Financeira desenhado para Portugal pela Troika entre 2011 e 2013, foram aplicadas as conhecidas "políticas de austeridade", visando a recuperação da economia nacional. Segundo Mark Blyth (2013), estas políticas provocam intencionalmente processos de deflação, gerando um ajustamento da economia através dos salários, dos preços e da despesa pública. A finalidade é o restabelecimento da competitividade e a injeção de confiança nos investidores. Estes voltarão a colocar o seu dinheiro num país que consegue controlar o défice e o endividamento públicos, um controlo que se relaciona positivamente com a expansão da atividade económica. Não é, pois, uma casualidade que o regime RNH tenha sido dinamizado num período como este e num país a necessitar da captação de recursos e de reconstruir a sua imagem no panorama internacional.

Sendo assim, a atração de investimento e a procura de capital humano qualificado são incentivadas mediante a concessão de uma vantagem fiscal face aos contribuintes do regime geral de contribuição, justificada pela 
existência de um interesse extrafiscal superior: a dinamização da economia. Os pressupostos implícitos neste raciocínio são, essencialmente, dois: 1) os efeitos positivos dessa dinamização serão superiores à potencial receita fiscal que se obteria se essa vantagem não existisse. Por outras palavras, os montantes que as pessoas abrangidas pelo regime $\mathrm{RNH}$ vão investir, gastar em bens de consumo ou gerar mediante as suas qualificações compensarão o valor dos impostos que não pagam ou que pagam em valores reduzidos; 2) sem a vantagem fiscal, essas pessoas não viriam para Portugal ou, pelo menos, reduzir-se-ia substancialmente a probabilidade de isso vir a acontecer.

\section{A racionalidade política do regime $\mathrm{RNH}$}

$\mathrm{O}$ regime de RNH estabelece uma vantagem fiscal que é igualmente uma exceção no sistema geral de tributação. Contudo, trata-se de uma exceção relativa se temos em conta o relatório "Os benefícios fiscais em Portugal" (Oliveira, 2019): há mais de 500 benefícios, distribuídos por mais de 60 diplomas legais, constituindo um sistema extremamente complexo e pouco transparente (ibidem: XXI). Esta secção explora o tipo de racionalidade política que inspira e legitima o regime RNH. A compreensão desta racionalidade permite uma abordagem aprofundada à vantagem outorgada ao RNH, assim como à noção de cidadania implícita e relacionada com a ideia de exceção ou "privilégio".

O conceito de racionalidade política procede dos estudos sobre governamentalidade (governmental studies) de inspiração foucaltiana (Burchell et al., 1991; Marinis, 1999; Dardot e Laval, 2013). Este conceito designa o conjunto de objetivos - políticos, sociais, económicos, militares, pedagógicos - que são perseguidos no exercício do poder assim como os princípios liberdade, justiça, equidade, prosperidade - em nome dos quais esse poder é aplicado. A racionalidade política envolve também uma conceção da natureza dos sujeitos que são governados, expressa mediante um vocabulário e discurso específicos (Burchell et al., 1991; Marinis, 1999; Dardot e Laval, 2013). Como já referimos, o regime RNH passa por estimular a economia nacional, o que exige o desenvolvimento de uma política fiscal com capacidade para atrair investimento e iniciativa empresarial. Ora esse investimento pode ser obtido através da criação de vantagens concretas para um conjunto de cidadãos. Esta exceção terá de ser legitimada de acordo com uma justificação específica, pois parece, à partida, disruptiva no seio das democracias liberais (Agamben, 2010). Isto é, convive com princípios genéricos de estruturação da comunidade política como a igualdade ou a equidade consagradas nos textos jurídicos, no discurso político ou nas 
declarações das agências estatais quando justificam a sua ação com base no fornecimento de oportunidades iguais a todos os cidadãos.

A questão da cidadania é a chave explicativa para compreendermos a legitimação da vantagem que deriva da aplicação do regime RNH. Jelena Džankíc (2019) oferece uma visão abrangente e complexa sobre a concessão, à escala global, da cidadania em troca de investimento. A cidadania pode ser entendida como um ponto nodal onde se encontram noções de pertença, identidade, direitos e obrigações estreitamente vinculadas à construção da nacionalidade e da comunidade política. Como tal, qualquer definição estática e apriorística de cidadania corre o risco de não captar a sua natureza multidimensional e histórica. $\mathrm{O}$ que, de facto, seria o mesmo que ignorar as transformações contemporâneas que têm ocorrido a partir da ampliação progressiva de direitos - igualdade perante a lei, sufrágio universal, proteção social -, do aumento da mobilidade geográfica, da transformação dos vínculos afetivos e identitários relacionados com o Estado-nação e do fenómeno da globalização, que abriu a porta a um enfoque mais instrumental da condição de cidadão. Para Džankíc (2019), a cidadania apresenta duas dimensões: 1) uma dimensão externa que remete para o reconhecimento do passaporte por parte de outros Estados, o direito de retorno ao país do qual se é cidadão e a proteção diplomática; 2) uma dimensão interna que remete para a pertença a uma comunidade política dentro da qual são exercidos direitos e satisfeitas obrigações num marco de lealdade à própria comunidade.

A tese de Džankíc tem a ver com a desarticulação entre estas duas dimensões, ou entre as suas componentes internas e a rearticulação com outras componentes. Assim, a dimensão externa pode rearticular-se com elementos mercantis quando é concedido um passaporte nacional às pessoas que investem um dado volume de dinheiro num país: o caso de Malta, dentro da UE. A dimensão interna também sofre desarticulações quando se separam a dimensão legal e política graças à perda de importância do fator territorial. Por exemplo, um cidadão de um país membro da UE tem todos os direitos inerentes à cidadania europeia quando reside num outro país membro, exceto os direitos políticos relacionados com o voto nas eleições legislativas e presidenciais (quando aplicável). A questão da lealdade também é suscetível de desarticulação, uma vez que se podem manter esses direitos de cidadania sem renunciar à nacionalidade de origem.

A abordagem de Džankíc descura a questão dos impostos na conformação da cidadania, ponto absolutamente central para este artigo. No âmbito das democracias liberais contemporâneas é possível falar da existência de um contrato social fiscal (Leroy, 2008), que pressupõe a transparência das 
finanças públicas e a disponibilidade de informação comparada num quadro de eleição política sobre a estrutura e a finalidade dos impostos. Os impostos podem financiar despesas, regular a economia privilegiando ou penalizando setores e bens, redistribuir recursos com uma pretensão social (incentivar a criação, a inovação, a filantropia), proteger o desenvolvimento e o ambiente de um território ou contribuir para as políticas de interesse geral suportando os serviços públicos. Isto é, os impostos estão estreitamente relacionados com a dimensão social da cidadania identificada por Thomas Humphrey Marshall (Shafir, 1998). Graças a eles, os cidadãos têm acesso a meios de proteção face a eventos negativos (doença, perda do emprego, acidentes laborais, assistência na velhice) assim como a garantia de um nível de bem-estar mínimo na educação, na saúde e nas pensões que lhes permitam ser autónomos na tomada de decisão de certas áreas da vida.

Como tal, podemos afirmar que o regime RNH constitui uma amostra de rearticulação da cidadania com elementos de cariz mercantil. Emerge um novo critério, o ius pecuniae, onde o vínculo primário entre o indivíduo e a comunidade política é o capital (Džankíc, 2019: cap. 3). Esses elementos concretizar-se-ão no valor económico associado ao património ou ao capital intelectual do regime $\mathrm{RNH}$, assim como no incentivo à maximização do interesse individual mediante a concessão de uma vantagem fiscal. Ao abrigo deste regime espera-se, pois, obter um tipo de cidadão concreto.

Sobre este ponto há poucas dúvidas. Uma prova disso é o Plano Estratégico para as Migrações - 2015-2020 (Alto Comissariado para as Migrações, 2015), onde se refere que Portugal sempre adotou um enfoque passivo no terreno das migrações, centrado nas ideias de receber, acolher e integrar. Esse enfoque, segundo o Plano, deve ser modernizado e ampliado promovendo soluções criativas para a economia nacional. Uma dessas soluções passa pela captação de imigrantes relevantes pelas suas competências e talentos (Köppe, 2003; Menz, 2016). Numa entrevista ao jornal Expresso, Pedro Lomba, secretário de Estado Adjunto do ministro Adjunto e do Desenvolvimento Regional entre 2013 e 2015, defendia a necessidade de realizar escolhas no perfil dos imigrantes que Portugal devia atrair: "ao realizar ações de promoção do país, deve selecionar os imigrantes a quem se dirige” (Bastos, 2014).

A articulação da cidadania com elementos mercantis conduz-nos a uma noção económica da própria cidadania (Devoretz e Irastorza, 2017). Sob esta perspetiva, a condição de cidadão assemelha-se à condição de membro de um clube. Genericamente, qualquer clube aceita novos membros sempre que estes respeitem as regras estabelecidas e, sobretudo, sempre que os benefícios que geram sejam superiores aos custos que acarreta a sua integração. 
Como tal, o regime RNH inclui um indivíduo do qual se espera que faça crescer a atividade económica (mediante investimentos, consumo e conhecimento) além dos custos vinculados à sua presença, isto é, os procedimentos administrativos relacionados com a sua regularização e a receita fiscal não obtida devido à vantagem contributiva que possui.

A questão dos bens públicos é aqui extremamente relevante. Alguma literatura clássica (Tiebout, 1956) e mais recente (Ruhs e Martin, 2008) sobre este tema reflete sobre o número ótimo de membros que o clube deve ter para que estes usufruam satisfatoriamente dos serviços oferecidos. Traçando uma analogia com a sociedade, tratar-se-ia de determinar qual é o número ótimo de residentes para os quais pode ser produzido um serviço público com o custo mais baixo possível. Assume-se que a utilidade que se retira de um serviço público depende do número de pessoas que partilham os benefícios desse serviço. Consequentemente, o tamanho ótimo seria encontrado no ponto de equilíbrio entre o benefício marginal e o custo marginal de incorporar um novo membro. Entendida desta forma, a noção de cidadania económica indica que é recomendável a inclusão do regime $\mathrm{RNH}$ quando o custo marginal da sua incorporação no país de acolhimento seja inferior ao benefício marginal que produz. Neste sentido, é preciso assinalar que, teoricamente, os RNH são pessoas com recursos significativos, o que provavelmente os torne menos propensos ao consumo de alguns serviços públicos ou mais seletivos na sua utilização. Assim, a sociedade como clube acabaria por poupar, uma vez que os novos membros até poderiam reduzir os custos dos mais antigos na produção e manutenção dos serviços públicos. $\mathrm{Ou}$, dito de um outro modo, o regime $\mathrm{RNH}$ não apareceria aos olhos da comunidade como sendo prejudicial para os outros indivíduos.

Finalmente, é necessário dedicar uma breve reflexão ao papel do Estado nestes processos de articulação, desarticulação e rearticulação mercantil da cidadania. Contrariamente a certas visões redutoras e simplificadoras, o papel que a racionalidade política neoliberal outorga ao Estado é central. Não estamos perante um Estado ausente, nem um Estado mínimo ou reduzido, nem um simples "vigilante noturno". Tais visões costumam interpretar o neoliberalismo como um processo de retirada do Estado da atividade económica para que esta funcione única e exclusivamente segundo a ordem natural e espontânea dos princípios do mercado. O próprio Friedrich A. Hayek, um dos autores seminais da tradição intelectual neoliberal, dificilmente concordaria com essa perspetiva. Não em vão afirmou que o importante não é o volume da intervenção estatal, mas sim o caráter dessa intervenção (Rodrigues e Teles, 2011:36). Como tal, o neoliberalismo reserva para o Estado um papel essencial: a promoção, disseminação e dinamização 
de mecanismos de mercado de forma a coordenar as diferentes atividades sociais. As suas funções são reorientadas nesta direção com a finalidade de introduzir elementos de concorrência nessa coordenação. Desse modo, através de parcerias público-privadas, subcontratações, subsídios ou incentivos, o Estado age como facilitador de diferentes áreas de negócio para a iniciativa privada, em setores centrais como as telecomunicações, a rede rodoviária, a energia, a saúde, as pensões ou a saúde (Rodrigues e Teles, 2011). No regime RNH, esse papel é cumprido, uma vez o Estado português é essencial para o desenho administrativo-legal de um mecanismo mercantil de rearticulação económica da cidadania.

\section{A subjetividade individual associada ao regime $\mathrm{RNH}$}

Num contexto de concorrência global, uma parte da dinamização da atividade económica dependerá da atração de contingentes específicos de indivíduos. Neste ponto, governar é gerir seletivamente os fluxos migratórios. Essa gestão, realizada em nome do dinamismo económico, envolve a reinvenção de uma cidadania articulada, como vimos, com o mercado, e que não é coerciva nem imposta num sentido disciplinar. A seletividade dos potenciais candidatos ao regime $\mathrm{RNH}$ tem em conta a autonomia dos próprios indivíduos, que são pensados enquanto sujeitos livres que tomam decisões de forma independente e segundo critérios particulares. Consequentemente, os objetivos de governo terão de estar alinhados com essa autonomia. No contexto de concorrência global de atração do investimento e do capital humano qualificado, são lançados ao mercado sinais informativos que adotam a forma de vantagens fiscais. Assim, sujeitos com um valor competitivo diferencial efetuam escolhas num mercado global dinamizado pelos Estados em prol da maximização de tal valor. E uma das possibilidades de maximização é, obviamente, pagar menos ou não pagar impostos.

O regime RNH prescreve um tipo de sujeito associado a um padrão de subjetividade expectável, interligada com a estrutura e procedimento dispostos pelo Estado para a gestão da mobilidade dos potenciais beneficiários do regime. Essa subjetividade ajusta-se a essa estrutura e a esse procedimento, reforçando-o (Benson e O'Reilly, 2018). As dimensões principais desta subjetividade são as seguintes:

a) $\mathrm{O}$ indivíduo que usufrui do regime $\mathrm{RNH}$ é um agente que racionaliza e maximiza as suas oportunidades económicas em função das possibilidades oferecidas pelo sistema global de concorrência fiscal.

b) Essas oportunidades são concretizadas mediante escolhas que o agente racionaliza e compreende como sendo livres e autónomas. 
A decisão apresenta-se individualizada e desprovida de reflexão acerca das estruturas e procedimentos que fazem com que seja possível. É, pois, uma decisão despolitizada e descontextualizada.

c) $\mathrm{O}$ agente assume estar na posse de um leque de recursos (qualificações, conhecimento, capital) comparativamente superiores aos recursos habitualmente disponíveis entre os imigrantes laborais conotados com a força de trabalho, a procura de emprego e a sobrevivência material.

d) Este agente dispõe de capacidade de cálculo, análise e avaliação, além de meios para assegurar a própria existência material. Possui, pois, clarividência na deteção das oportunidades e sentido de autogoverno.

e) A autoidentificação do agente não passa pelas categorias mais frequentes de mobilidade ou de imigração. Neste último caso, não se apresentam como imigrantes convencionais, dada a mais-valia que representam sob o formato de capital intelectual e/ou económico. Emancipados face às limitações materiais dos imigrantes laborais convencionais, reconhecem-se e são reconhecidos como imigrantes "desejáveis" ou "privilegiados". Esta autoconsciência de desejabilidade expressa-se em designações alternativas como "expatriado", "turista residente", "novo residente", "residente estrangeiro" (Benson e O’Reilly, 2018), "classe criativa" (Florida, 2010), "super-rico” (Hay, 2013) ou "migrante milionário” (Ley, 2010).

Os traços gerais deste tipo de subjetividade encontram-se registados na literatura sobre migrações. No interregno da mobilidade em prol do bem-estar material e vital, das oportunidades fiscais, da realização pessoal, da qualidade de vida e do turismo, emergem categorias de análise onde esta subjetividade parece estar presente, tais como migração privilegiada, turismo residencial (Croucher, 2012), migração por estilo de vida (Benson e O’Reilly, 2018), migração recreativa, migração sazonal, proprietários de segundas casas ou expatriados (Benson e O'Reilly, 2009). Apesar de cada uma destas categorias designar realidades diferentes, existe uma linha transversal entre todas que aponta para condições económicas preferenciais, uma maximização de oportunidades e certos valores de cariz individualista.

A questão principal é sabermos como se traduz em termos materiais esta subjetividade, isto é, estabelecer o vínculo com as condições sociais nas quais se alimenta e que, simultaneamente, contribui a criar e reforçar. A tradução material da subjetividade pode ser visualizada nas relações entre o regime RNH e o setor imobiliário. Estas relações devem ser enquadradas no processo mais amplo de financeirização da habitação em Portugal 
(Rodrigues et al., 2016), que designa o peso crescente da finança e dos seus agentes na provisão deste bem. A habitação, entendida como um ativo transacionável no mercado, ou um ativo financeiro valorizado mediante o valor de troca, alimenta fluxos monetários extremamente relevantes para o Estado e para os agentes económicos privados. O ciclo de financeirização arranca com a entrada de Portugal na UE, e o consequente protagonismo da banca na concessão de créditos e as bonificações fiscais para quem subscreve um empréstimo para comprar uma casa. Um segundo momento de extrema relevância neste ciclo coincide com o Programa de Assistência Económica e Financeira na sequência da crise financeira de 2008, e a intervenção no país da Troika (formada pelo Fundo Monetário Internacional, pelo Banco Central Europeu e pela Comissão Europeia). A partir daqui, aprofunda-se a liberalização do mercado imobiliário, são facilitados os despejos e a cessação dos contratos graças ao Novo Regime de Arrendamento Urbano e são criados incentivos ao investimento estrangeiro e ao desenvolvimento do alojamento local (Santos, 2019).

Segundo Joaquim Montezuma e Jennifer McGarrigle (2018), Lisboa encontra-se hoje integrada no segundo anel mundial de cidades que atraem investimento imobiliário, alimentadas pela interligação dos fluxos financeiros, imigração e turismo. As oportunidades abertas têm servido para diversas finalidades como a utilização sazonal, o alojamento turístico, a lavagem de dinheiro ou a proteção de ativos face à instabilidade política e económica nos países de origem dos investidores. Durante muito tempo, os protagonistas destes investimentos foram as elites transnacionais, capazes de manter níveis elevados de mobilidade geográfica. Não obstante, nos últimos anos, é possível constatar a existência de classes médias endinheiradas, também com um verniz transnacional, e ligadas a estes investimentos a partir de programas como os Vistos Gold (Ampudia de Haro e Gaspar, 2019) ou o regime RNH. Montezuma e McGarrigle (2018: 8), com base em entrevistas a mediadores imobiliários e advogados, estimam que cerca de $25 \%$ das transações imobiliárias realizadas por estrangeiros no centro de Lisboa correspondam a indivíduos enquadrados no regime RNH. São identificados com o perfil lifestyle income optimizers, ou seja, pré-reformados, reformados e profissionais com elevadas qualificações atraídos pela fiscalidade e pelo baixo custo da vida comparativamente aos seus países de origem. Estes indivíduos são, pois, capazes de práticas de geoarbitragem em função das oportunidades que oferece o mercado fiscal global para maximizar os seus recursos, desempenhando assim um papel fundamental nos processos de gentrificação da cidade (Mendes, 2017; Mendes e Jara, 2018), sobretudo aqueles relacionados com a especulação imobiliária 
e com os desequilíbrios provocados neste âmbito (Lestegás et al., 2018). Insistimos, pois, na importância desse papel dentro de um processo mais amplo que tem a ver com a financeirização da habitação, a crise económico-financeira de 2008 e a aplicação de políticas de austeridade subsequentes.

\section{Conclusão}

O regime RNH é um programa presidido por uma racionalidade política neoliberal. Este tipo de racionalidade entende que a criação de mecanismos de mercado é o procedimento adequado para a coordenação das atividades sociais ou para responder às necessidades económicas, financeiras, laborais, culturais ou educativas da população. Em consonância com esta ideia, esta racionalidade pressupõe a necessidade de economizar no exercício do poder, ou seja, que os indivíduos invistam recursos, energia e tempo no seu autogoverno. A partir daí, corresponde ao Estado o papel de promotor e facilitador desses mecanismos de mercado mediante a criação, a afinação e o desenho de estruturas legais. A sua intervenção é, neste ponto, decisiva e não corresponde à posição de um Estado em retirada do planeamento económico e fiscal. Esta racionalidade política possui um caráter transversal, isto é, atravessa as diferentes opções partidárias que habitualmente identificamos como sendo de direita, centro-direita, liberais ou de centro-esquerda. De facto, o regime RNH é criado sob um governo do PS entre 2005 e 2011, continuado pelo governo do Partido Social Democrata (PSD) e o Centro Democrático e Social (CDS) entre 2011 e 2015 e mantido e aprofundado por um novo governo do PS até hoje. A sua transversalidade mostra que se trata de um modo aprofundado de pensar os mecanismos de articulação da sociedade, muito além da disputa pontual entre partidos políticos.

Mas como é que estes princípios se aplicam ao regime RNH? O Estado participa no mercado fiscal internacional apresentando uma oferta competitiva, que passa pela atração de capital financeiro e de capital humano em troca de benefícios e isenções tributárias. A solução oferecida para captar esses recursos é o desenho de um produto, o regime $\mathrm{RNH}$, diferenciado face a outros produtos internacionais equivalentes. Torna-se, pois, um agente num mercado onde interage com outros agentes-Estado. Como produto diferenciado e, simultaneamente, similar aos existentes no mercado, este regime pressupõe a existência de um tipo de destinatário específico que preencha os requisitos legais estabelecidos em termos de qualificações e nível de rendimentos. Mas este pressuposto também inclui um padrão de subjetividade associada aos destinatários, com capacidades de autogoverno e recursos materiais e intelectuais. 
Este tipo de racionalidade não está apenas presente na conceção do regime RNH ou no tipo de destinatário a que se destina. Emerge igualmente na lógica de avaliação do próprio programa, cuja pertinência depende, em grande medida, de o impacto do investimento e do capital humano ser suficientemente significativo para compensar a receita fiscal que não se obtém devido às vantagens tributárias (Crisóstomo, 2018). A mesma racionalidade que inspira o programa parece determinar a sua avaliação. De facto, as reavaliações pontuais do programa não têm fugido à lógica neoliberal, e surgem na sequência de queixas formais por parte da Suécia e da Finlândia perante a isenção tributária concedida aos reformados de ambos os países a residirem em Portugal (Lusa, 2017; Público, 2018). Os governos sueco e finlandês exigiram a eliminação dessa isenção sob a ameaça de rever os acordos que evitam a dupla tributação entre Portugal e os dois países nórdicos. Com essa revisão, os reformados finlandeses e suecos teriam de ser tributados nos seus países de origem, esvaindo-se desta forma a vantagem fiscal portuguesa. ${ }^{3}$ A resposta portuguesa é, de novo, alinhada com a lógica mercantil: afinar o programa para não perder competitividade, ao mesmo tempo que se procura garantir uma concorrência não lesiva para os parceiros da UE. Consequentemente, a partir de 2020, os reformados passaram a pagar uma taxa de $10 \%$ sobre as suas pensões, tentando também que o programa se tornasse "mais ativo" na captação de capital humano qualificado. O que parecem sugerir os dados da Tabela 1 anteriormente apresentada, é que o programa pode estar a ser mais procurado entre alguns dos seus destinatários (sobretudo suecos, franceses e italianos) como um meio de obter vantagens fiscais na reforma - e não tanto como uma via para incorporar pessoal qualificado em Portugal.

A análise crítica que desenvolvemos neste artigo permite efetuar uma série de considerações finais. Em primeiro lugar, e como assinalámos previamente, o regime RNH é um mecanismo de mercado desenvolvido pelo Estado. Não é um Estado desativado nem retraído, mas sim um Estado que intervém e dinamiza em nome do desenvolvimento do país. Mas essa intervenção dinamizadora também tem efeitos cívicos, isto é, efeitos na vida da comunidade política: a constituição de um grupo de cidadãos a partir do cidadão-investidor ou do cidadão-capital humano, visto através do prisma diferenciador do volume de capital que trazem consigo.

3 Com efeito, a 2 de junho de 2021, o Parlamento sueco anulou o acordo fiscal com Portugal, podendo a partir de 1 de janeiro de 2022 cobrar impostos sobre as pensões pagas a cidadãos suecos residentes em Portugal (Lusa, 2021). 
Em segundo lugar, este tipo de cidadão coloca num plano secundário elementos essenciais para a noção de cidadania. Como tal, a participação, o compromisso com a comunidade, a responsabilidade partilhada ou a solidariedade esmorecem como conteúdos cívicos face ao vínculo primário entre este cidadão, o Estado e a comunidade. O cidadão económico mantém, à partida, uma relação instrumental com a sociedade de receção numa lógica de free rider (Jopke, 2019) que, até certo ponto, não é surpreendente, visto que o regime RNH também concebe este cidadão em termos instrumentais como fonte portadora de capitais materiais ou intelectuais.

Em terceiro lugar, o regime RNH constitui uma dupla exceção. Por um lado, face aos restantes contribuintes, na medida que fica à margem o princípio da equidade contributiva. Por outro lado, face a outros candidatos a residirem em Portugal, na medida que estes possuem uma via preferencial e facilitada na sua sedentarização no país. A criação da exceção, como vimos, é justificada em termos técnicos - dinamização da economia mediante uma nova estratégia fiscal - e, por isso, convenientemente despolitizada. Assim, a exceção tecnicamente legitimada é usada para selecionar indivíduos relevantes como portadores de capital e como agentes de cálculo e de maximização (Ong, 2006). Implicitamente, aos cidadãos não abrangidos por esta exceção está a ser pedido o sacrifício de aceitar a não-equidade para, desse modo, retirar benefícios do tratamento excecional outorgado aos RNH. Esta dimensão de "sacrifício" expressa uma continuidade retórica e ideológica com o discurso do sacrifício que vigorou como justificação geral das políticas de austeridade (Alonso et al., 2016). Mas, neste caso, o sacrifício não implica só a aceitação da não equidade como também a promoção da desigualdade social, ao outorgar um tratamento favorável a quem dispõe de condições materiais, económicas e intelectuais já por si propícias. Em suma, o interesse comum, conceptualizado como dinamização económica, exige a aceitação de exceções para, se nos for permitida a expressão, "cidadãos excecionais" ou "privilegiados".

O regime RNH não é, exclusivamente, um artefacto fiscal. Uma visão redutora deste objeto escamoteia as dimensões sociológicas que até aqui fomos ilustrando. É, pois, muito mais do que não pagar ou pagar menos impostos. Estamos perante um regime afim a um modelo de cidadão económico nascido de uma racionalidade política neoliberal, instalada, há muito, nas sociedades europeias.

Revisto por Ana Sofia Veloso 


\section{Referências bibliográficas}

Agamben, Giorgio (2010), Estado de excepção. Lisboa: Edições 70. Tradução de Miguel Freitas da Costa [ed. orig. 2003].

Alonso, Luis Enrique; Fernández Rodríguez, Carlos Jesús (orgs.) (2012), La financiarización de las relaciones salariales. Una perspectiva internacional. Madrid: Los Libros de la Catarata.

Alonso, Luis Enrique; Fernández Rodríguez, Carlos Jesús; Ibáñez Rojo, Rafael (2016), "De la moral del sacrificio a la conciencia de la precariedad. Un análisis cualitativo de los discursos sobre la evolución de la crisis en España”, Política y Sociedad, 53(2), 353-379.

Alto Comissariado para as Migrações (2015), Plano Estratégico para as Migrações 2015-2020. Consultado a 01.05.2020, em https://www.acm.gov.pt/documents/ 10181/222357/PEM_net.pdf/3a515909-7e66-41e8-8179-e3aa5e0c7195.

Ampudia de Haro, Fernando; Gaspar, Sofia (2019), "Visados dorados para inversores en España y Portugal: residencia a cambio de dinero", Arbor. Ciencia, Pensamiento, Cultura, 195(791), a495.

Bastos, Joana Pereira (2014), "Portugal deve selecionar os imigrantes", Expresso, 19 de dezembro. Consultado a 01.05.2020, em https://expresso.pt/dossies/diario/ portugal-deve-selecionar-os-imigrantes $=\mathfrak{f} 903520$.

Benson, Michaela; O'Reilly, Karen (2009), "Migration and The Search for a Better Way of Life: A Critical Exploration of Lifestyle Migration”, The Sociological Review, 57(4), 608-625.

Benson, Michaela; O'Reilly, Karen (2018), Lifestyle Migration and Colonial Traces in Malaysia and Panama. Oxford, UK: Palgrave MacMillan.

Blyth, Mark (2013), Austerity: The History of a Dangerous Idea. New York: Oxford University Press.

Burchell, Graham; Gordon, Colin; Miller, Peter (orgs.) (1991), The Foucault Effect: Studies in Governmentality. London: Harvester Wheatsheaf.

Clark, Gordon; Thrift, Nigel; Tickett, Adam (2004), "Performing Finance: The Industry, the Media and Its Image", Review of International Political Economy, 11(2), 289-310.

Crisóstomo, Pedro (2018), "Benefício que isenta de IRS residentes estrangeiros custa 350 milhões", Público, 22 de junho. Consultado a 01.05.2020, em https://www.publico.pt/ 2018/06/22/economia/noticia/beneficio-que-isenta-de-irs-residentes-estrangeiros-custa-350-milhoes-1835444.

Croucher, Sheila (2012), "Privileged Mobility in an Age of Globality", Societies, 2, 1-13.

Dardot, Pierre; Laval, Christian (2013), The New Way of the World: On Neo-Liberal Society. London: Verso.

Devoretz, Don J.; Irastorza, Nahikari (2017), "Economic Theories of Citizenship?", Discussion Paper Series IZA DP, no 10495. Bonn: IZA Institute of Labor Economics. 
Džankíc, Jelena (2019), The Global Market for Investor Citizenship. London: Palgrave MacMillan.

Epstein, Gerald A. (org.) (2005), Financialization and the World Economy. Cheltenham, Camberley, Northampton, MA: Edward Elgar Publishing.

Erturk, Ismail; Froud, Julie; Solari, Stefano; Williams, Karel (2005), “The Reinvention of Prudence: Household Savings, Financialisation and Forms of Capitalism”, CRESC Working Paper Series, 11. Consultado a 31.07.2021, em http://hummedia.manchester. ac.uk/institutes/cresc/workingpapers/wp11.pdf.

Florida, Richard (2010), La classe creativa. La transformación de la cultura del trabajo $y$ del ocio en el siglo XXI. Barcelona: Paidós.

Foucault, Michel (2010), Nascimento da biopolítica. Lisboa: Edições 70. Tradução de Pedro Elói Duarte [ed. orig. 1979].

Fougner, Tore (2008), "Neoliberal Governance: The Role of Competitiviness Indexing and Country Benchmarking”, Millenium: Journal of International Studies, 37(2), 303-326.

Genschel, Phillip; Schwarz, Peter (2011), “Tax Competition: A Literature Review”, Socio-Economic Review, 9, 339-370.

Harrington, Brooke (2008), Pop Finance. Investments Clubs and the New Investor Populism. Princeton: Princeton University Press.

Hay, Iain (org.) (2013), Geographies of the Super-Rich. Cheltenham, UK/Northampton, MA, USA: Edward Elgar Publishing.

Heilbron, Johan (2005), “Taking a Stock: Toward a Historical Sociology of Financial Regimes”, Economic Sociology. The European Electronic Newsletter, 7(1), 3-17.

Jopke, Christian (2019), “The Instrumental Turn of Citizenship”, Journal of Ethnic and Migration Studies, 45(6), 858-878.

Köppe, Olaf (2003), “The Leviathan of Competitiviness: How and Why Do Liberal States (Not) Accept Unwanted Inmigration”, Journal of Ethnic and Migration Studies, 29(3), 431-448.

Langley, Paul (2007), "Uncertain Subjects of Anglo-American Financialization”, Cultural Critique, 65, 67-91.

Laurent, Eloi (2007), "From Competition to Constitution: Races to Bottoms and the Rise of 'Shadow' Social Europe”, CES Working Paper, 137.

Leroy, Marc (2008), “Tax Sociology”, Socio-logos, 3. Consultado a 01.05.2020, em http:// journals.openedition.org/socio-logos/2073.

Lestegás, Iago; Lois-González, Rubén Camilo; Seixas, João (2018), “The Global Rent Gap of Lisbon's Historic Centre”, International Journal of Sustainable Development and Planning, 13(4), 683-694.

Ley, David (2010), Millionaire Migrants. Trans-Pacific Lines. Oxford, UK/Malden, MA, USA: Wiley-Blackwell.

Lobo, Carlos (2010), "Política fiscal em tempos de recessão", Revista de Finanças Públicas e Direito Fiscal, 3, 11-36. 
Lobo, Carlos (2017), “Sugestão: um regime interno de Residentes Não Habituais para regiões de baixa densidade”, Jornal Económico, 21 de setembro. Consultado a 01.05.2020, em https://jornaleconomico.sapo.pt/noticias/sugestao-um-regime-interno-de-residentesnao-habituais-para-regioes-de-baixa-densidade-211732.

Lusa (2017), "Ministra sueca critica isenção de impostos concedida a pensionistas estrangeiros em Portugal. 'Inaceitável'”, Expresso, 23 de fevereiro. Consulado a 01.05.2020, em https://expresso.pt/internacional/2017-02-23-Ministra-sueca-critica-isencao-deimpostos-concedida-a-pensionistas-estrangeiros-em-Portugal.-Inaceitavel.

Lusa (2021), "Parlamento sueco anula acordo fiscal com Portugal", Eco - Economia Online, 2 de junho. Consultado a 04.06.2021, em https://eco.sapo.pt/2021/06/02/ parlamento-sueco-aprova-denuncia-de-acordo-fiscal-com-portugal/.

Marinis, Pablo de (1999), "Gobierno, gubernamentalidad, Foucault y los anglofoucaultianos (un ensayo sobre la racionalidade política del neoliberalismo)”, in Ramón Ramos Torre; Fernando García Selgas (orgs.), Globalización, riesgo, reflexividad. Tres temas de la teoría social contemporánea. Madrid: Centro de Investigaciones Sociológicas, 73-103.

Martin, Randy (2002), Financialization of Daily Life. Philadelphia: Temple University Press. Mendes, Luís (2017), "Gentrificação turística em Lisboa: neoliberalismo, financeirização e urbanismo austeritário em tempos de pós-crise capitalista 2008-2009”, Cadernos Metrópole, 19(39), 479-512.

Mendes, Luís; Jara, Ana (2018), "Supergentrificação e capitalismo financeirizado: as novas fronteiras do espaço-capital na Colina de Santana, Lisboa”, Cadernos Metrópole, 20(43), 769-796.

Mendes, Marta Filipa Ramos (2011), "O novo regime fiscal do residente não habitual (análise à luz do Princípio da Não Discriminação no Direito Europeu) ”. Dissertação de Mestrado em Ciências Jurídico-Económicas, Universidade do Porto, Porto, Portugal.

Menz, Georg (2016), "Framing Competitiviness: The Advocacy of Migration as an Essential Human Resources Strategy in Europe”, Journal of Ethnic and Migration Studies, 42(4), 625-642.

Mesquita, Raquel (2014), "Portugal o novo 'paraíso fiscal' para os estrangeiros - Regime fiscal dos residentes não habituais e os golden visas”. Dissertação de Mestrado em Direito Fiscal, Universidade Católica Portuguesa, Lisboa, Portugal.

Montezuma, Joaquim; McGarrigle, Jennifer (2018), "What Motivates International Homebuyers? Investor to Lifestyle 'Migrants' in a Tourist City", Tourism Geographies, 21(2), 214-234.

Oliveira, Francisca Guedes de (coord.) (2019), Os benefícios fiscais em Portugal. Conceitos, metodologia e prática. Lisboa: Centro de Estudos Fiscais e Aduaneiros, Autoridade Tributária e Aduaneira, Ministério das Finanças. Consultado a 01.05.2020, em https://info.portaldasfinancas.gov.pt/pt/dgci/divulgacao/Area_Beneficios_Fiscais/ Documents/Cad_CTF_217_Os_Beneficios_Fiscais_em_Portugal.pdf. 
Ong, Aihwa (2006), Neoliberalism as Exception. Mutations on Citizenship and Sovereignity. Londron: Duke University Press.

Platform for Tax Good Governance (2018), Discussion Paper for the Platform for Tax Governance, 12/09/18. Bruxelles: European Comission - Directorate-General Taxation and Customs Union. Consultado a 01.05.2020, em https://ec.europa. eu/taxation_customs/sites/taxation/files/document_of_com_competitiveness_ and_taxation_docx_en.pdf.

PricewaterhouseCoopers (2014), “Europe's Best Kept Secret”. Consultado a 31.07.2021, em http://financedocbox.com/Tax_Planning/94926303-Europe-s-best-kept-secret. html.

Público (2018), "Finlândia rompe acordo fiscal com Portugal e reformados perdem isenção de IRS”, Público, 25 de maio. Consultado a 01.05.2018, em https://www. publico.pt/2018/05/25/economia/noticia/finlandia-rompe-acordo-fiscal-comportugal-e-reformados-perdem-isencao-de-irs-1832108.

Rodrigues, João; Teles, Nuno (2011), "Portugal e o neoliberalismo como intervencionismo de mercado”, in José Reis; João Rodrigues (orgs.), Portugal e a Europa em crise. Para acabar com a economia da austeridade. Lisboa: Actual, 36-46.

Rodrigues, João; Santos, Ana Cordeiro; Teles, Nuno (2016), A financeirização do capitalismo em Portugal. Lisboa: Actual.

Ruhs, Martin; Martin, Philip (2008), "Numbers vs. Rights: Trade-Offs and Guest Worker Programs", The International Migration Review, 42(1), 249-265.

Santos, Ana Cordeiro (2018), "Financeirização do Estado, política de habitação e subsídios à especulação”, Le Monde Diplomatique - edição portuguesa, 142, 4-5.

Santos, Ana Cordeiro (coord.) (2019), A nova questão da habitação em Portugal. Uma abordagem de economia política. Coimbra: Conjuntura Actual/Almedina.

Schachar, Ayelet; Hirschl, Ran (2014), "On Citizenship, Satates and Markets", The Journal of Political Philosophy, 22(2), 231-257.

Scherrer, Amandine; Thirion, Elodie (2018), Citizenship by Investment (CBI) and Residency by Investment (RBI) Schemes in the EU. State of Play, issues and impacts. Bruxelas: EPRS - European Parlamentary Research Service.

Shafir, Gerson (org.) (1998), The Citizenship Debates. Minneapolis/London: University of Minnesota Press.

Silva, Alexandra Oliveira Pinho e (2015), “A tributação dos Residentes Não Habituais”. Dissertação de Mestrado em Contabilidade, Universidade de Aveiro, Aveiro, Portugal.

Tiebout, Charles (1956), “A Pure Theory of Local Expenditure”, Journal of Political Economy, 64(5), 416-424.

Trautvetter, Christoph; Winkler, Eric (2019), Competing for the Rich. Tax Exemptions and Special Scheme for the Rich. Bruxelas: The Greens/EFA Group in the European Parliament. Consultado a 01.05.2020, em http://extranet.greens-efa-service.eu/ public/media/file/1/5920. 
Xu, Xin; El-Ashram, Ahmed; Gold, Judith (2015), “Too Much of a Good Thing? Prudent Management of Inflows under Economic Citizenship Programs”, IMF Working Paper, WP/15/93. S.1.: International Monetary Fund.

\section{Legislação}

Decreto-Lei n. ${ }^{\circ}$ 249/2009, de 23 de setembro. Diário da República n. ${ }^{\circ}$ 185/2009, Série I de 2009-09-23. Lisboa: Ministério das Finanças e da Administração Pública.

Portaria n. ${ }^{\circ}$ 12/2010, de 7 de janeiro. Diário da República n. ${ }^{\circ}$ 4/2010, Série I de 2010-01-07. Lisboa: Ministério das Finanças e da Administração Pública.

Portaria n. ${ }^{\circ}$ 230/2019, de 23 de julho. Diário da República n. ${ }^{\circ}$ 139/2019, Série I de 2019-07-23. Lisboa: Ministério das Finanças e da Administração Pública.

\section{Fernando Ampudia de Haro}

Universidade Europeia

Campus de Santos, Av. D. Carlos I, n. ${ }^{\circ} 4,1200-649$ Lisboa, Portugal

Contacto: fernando.ampudia@universidadeeuropeia.pt

ORCID: https://orcid.org/0000-0001-6470-1912

\section{Sofia Gaspar}

Instituto Universitário de Lisboa - ISCTE-IUL, Centro de Investigação e Estudos de Sociologia Edifício Sedas Nunes - Sala 2W10, Av. das Forças Armadas, 1649-026 Lisboa, Portugal

Contacto: sofia.gaspar@iscte-iul.pt

ORCID: https://orcid.org/0000-0003-0002-6246

Artigo recebido a 11.05.2020

Aprovado para publicação a 24.06.2021

https://doi.org/10.4000/rccs. 11878 


\section{Neoliberal Political Rationality and Tax Regime: The Case of Non-Habitual Residents}

This paper examines the Non-Habitual Residents (NHR) tax regime from a sociological perspective. This analysis is twofold: it explores the social conditions for its emergence and next conceptualizes the political rationality that determines it, and the type of individual subjectivity regulating it. Methodologically, the analysis is developed according to the principles of Foucauldian governmentality studies. The paper is structured in three sections: 1) characterization and analysis of the evolution of the beneficiaries applying for this tax regime; 2) analysis of the emergence of NHR regime within the scope of 2008 financial crisis; and 3) the definition of the political rationality that inspires the regime. We conclude that this is a program conceived according to a neoliberal political rationality, and also a procedure to reproduce such rationality through the promotion of an "economic citizen" model.

Keywords: neoliberal policy; Non-Habitual Residents; socioeconomic analysis; tax benefits; tax regime.
Rationalité politique néolibérale et régime fiscale : le cas des résidents non habituels

Dans cet article, on analyse le régime fiscal des résidents non habituels $(\mathrm{RNH})$ à partir d'une perspective sociologique. Cette analyse exige une double réflexion : d'une part, examiner les conditions sociales existantes pour son émergence; et d'autre part, étudier la rationalité politique et le genre de subjectivité individuelle qui le soutient. Cette réflexion est basée, méthodologiquement, dans les hypothèses des études de gouvernementalité foucaldienne. L'article est structuré selon trois moments concrets : 1) la caractérisation et l'analyse de l'évolution des bénéficiaires de ce régime ; 2) l'analyse de l'émergence de ce régime dans le cadre de la crise financière de 2008 ; et 3) la définition de la rationalité politique qui inspire ce régime. On conclut que le régime RNH est un programme conçu selon des normes de rationalité politique néolibérale, en plus d'être une procédure de reproduction de cette même rationalité, en faisant la promotion d'un modèle de « citoyen économique ».

Mots-clés: analyse socio-économique; avantages fiscaux; politique néolibérale; régime fiscal; résidents non habituels. 